\title{
Spinal Melorheostosis: A Rare Cause for Thoracic Radiculopathy
}

\author{
K.R. RENJITH, D Ortho, DNB Ortho, AJOY PRASAD SHETTY, MS Ortho, DNB Ortho, RISHI MUKESH \\ KANNA P, MS Ortho, FNB Spine Surgery, MRCS, S RAJASEKARAN, MS, DNB, FRCS(Ed), MCH(Liv), FACS, \\ FRCS(Eng), PHD \\ Department of Spine Surgery, Ganga Medical Centre and Hospital Pvt Ltd, Coimbatore, Tamil Nadu, India
}

\begin{abstract}
Background: Symptomatic spinal melorheostosis is a rare entity, and its surgical management is even rarer. Our objective is to highlight the importance of considering spinal melorheostosis among the differential diagnosis of thoracic radiculopathy.

Methods: We report a case of melorheostosis involving the T9 vertebra presenting with unilateral radicular pain managed surgically by decompression and posterior stabilization.

Results: Our patient had complete symptomatic relief following surgical resection without any perioperative complications.

Conclusions: Spinal melorheostosis, although rare, forms an important differential diagnosis in patients presenting with thoracic radiculopathy where surgical management can be a viable option in cases refractory to conservative treatment

Level of Evidence: 5.
\end{abstract}

Tumor

Keywords: melorheostosis, thoracic radiculopathy, surgery

\section{INTRODUCTION}

Thoracic radiculopathy is less common than cervical and lumbar radiculopathy as evidenced by the paucity of literature in this regard. Thoracic disc disease and diabetes mellitus represent 2 of the most frequent etiologies for the development of thoracic radiculopathy. ${ }^{1}$

Melorheostosis is a noninheritable mesenchymal dysplasia commonly affecting the appendicular skeleton, more frequently the lower extremities. Involvement of the spine is uncommon, being mostly an asymptomatic incidental radiographic finding. Symptomatic spinal melorheostosis is limited to case reports. ${ }^{2-7}$

We report a case of melorheostosis involving T9 vertebra presenting with unilateral radicular pain in which decompression and posterior stabilization provided complete symptomatic relief.

\section{Case Report}

A 22-year-old female presented to our outpatient department with insidious onset mid-back pain of 6 months' duration. She had band-like pain radiating to the left upper quadrant of her abdomen that was progressively worsening. She denied any history of trauma or other constitutional symptoms. Clinical examination was unremarkable except for mild pain on rotatory movements of thoracic spine. Motor and sensory functions were intact with absent myelopathic signs. Plain radiographs showed a densely sclerotic left-sided lesion affecting the posterior elements of T9 vertebra (Figure 1). Computed tomography (CT) scan and magnetic resonance imaging (MRI) scans revealed an illdefined expansile sclerotic lesion involving the body of the T9 vertebra and posterior elements on the left side compromising neural foramina with similar lesions affecting the left inferior articular process of the T8 vertebra and the posterior portion of left eighth rib (Figures 2 and 3). A diagnostic nerve root block was not performed since the imaging findings were consistent with the diagnosis of melorheostosis causing left T9 nerve root compression. There were no appendicular skeletal manifestations. After informed consent, she was offered open excision biopsy and decompression with posterior stabilization in view of the widespread involvement of T9 


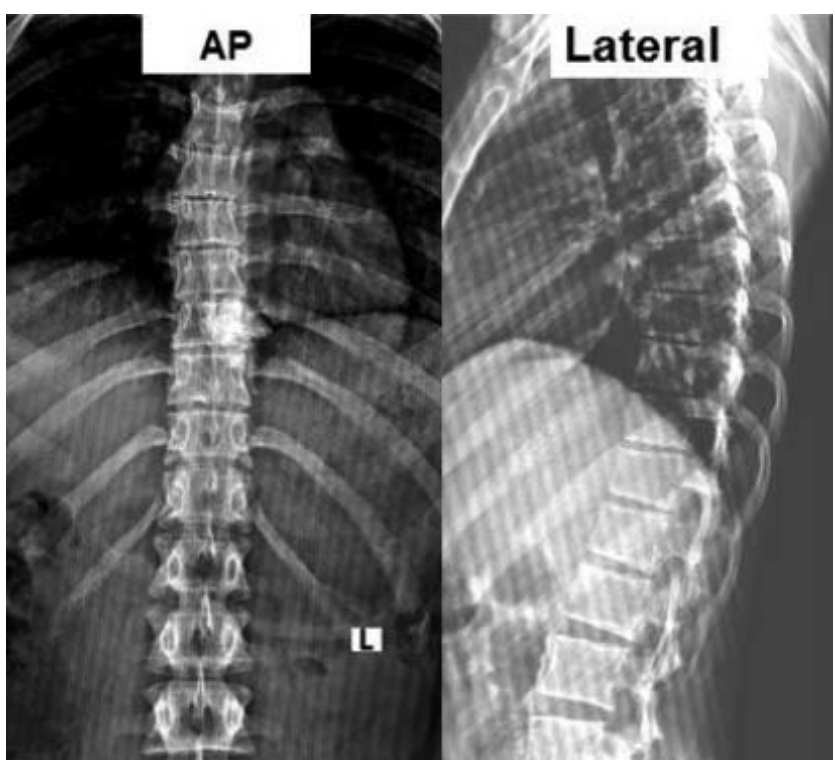

Figure 1. Preoperative $x$-rays showing sclerotic lesion over the T9 vertebra (anteroposterior and lateral views).

posterior elements with extension into the $\mathrm{T} 8$ and T9 articular processes. Peroperatively, the T9 lamina was found to be expansile and sclerotic. In the presence of intraoperative neuromonitoring, laminectomy was performed to excise the lesion with the aid of a high-speed burr and bone scalpel. The left T9 nerve root was adequately decompressed, and posterior stabilization was done from T8 to T10 using pedicle screw and rod fixation (Figure 4). There were no intraoperative or postoperative complications. The histopathology report confirmed the diagnosis (Figure 5). There was complete resolution of symptoms after resection, and at the follow-up visit after 3 months, 6 months, and 1 year, the patient remained asymptomatic. CT scan performed immediately postoperatively and at 1-year follow-up showed complete removal of the lesion with no evidence of recurrence (Figure 6).

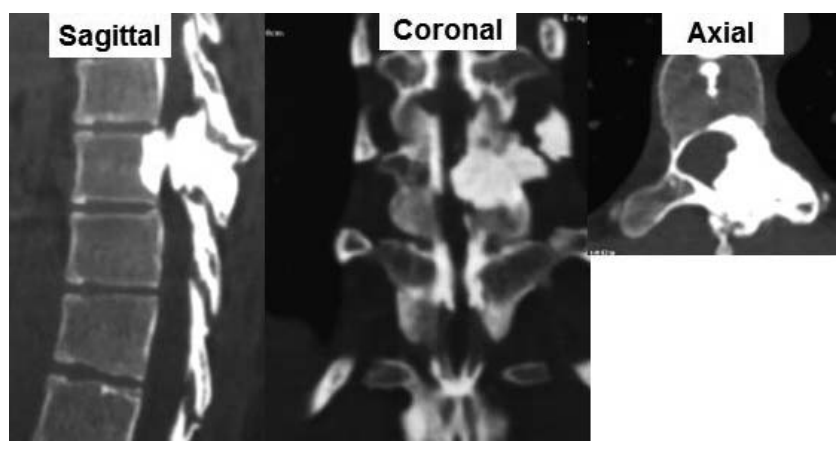

Figure 2. Preoperative computed tomography scan showing sclerotic lesion affecting the posterior elements of the T9 vertebra encroaching into the left foramen.

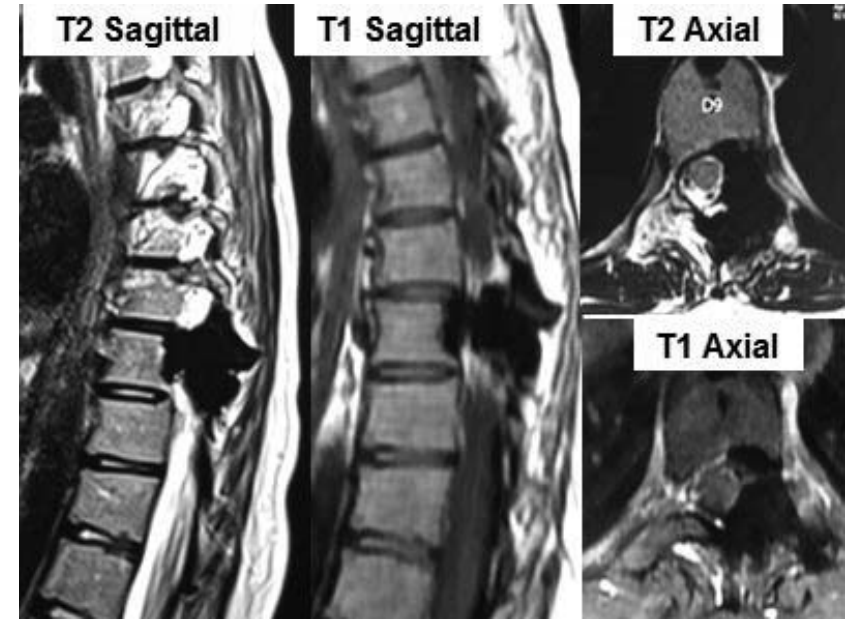

Figure 3. Preoperative magnetic resonance imaging scan. T1- and T2weighted images showing sclerotic lesions involving the body of the T9 vertebra extending to adjacent structures compromising left neural foramina.

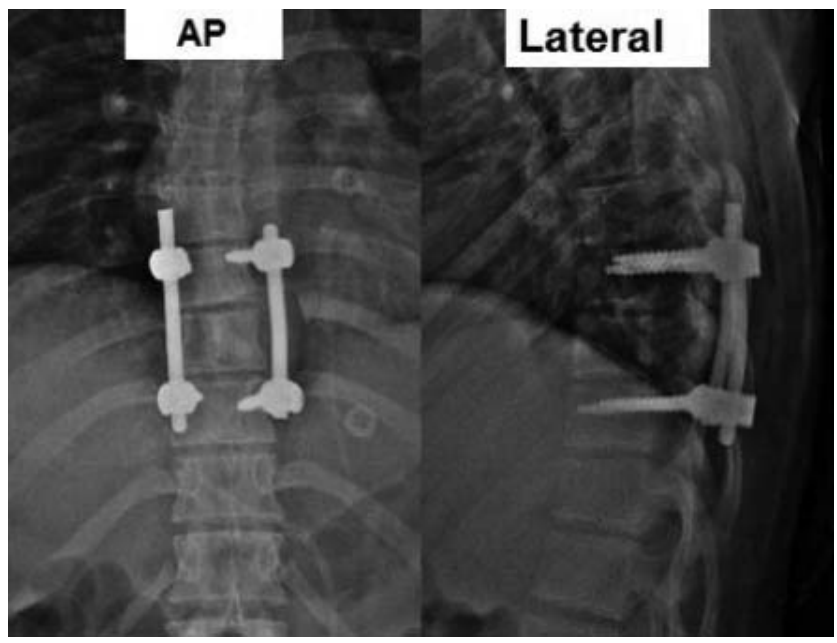

Figure 4. Postoperative $\mathrm{x}$-rays (anteroposterior and lateral views).
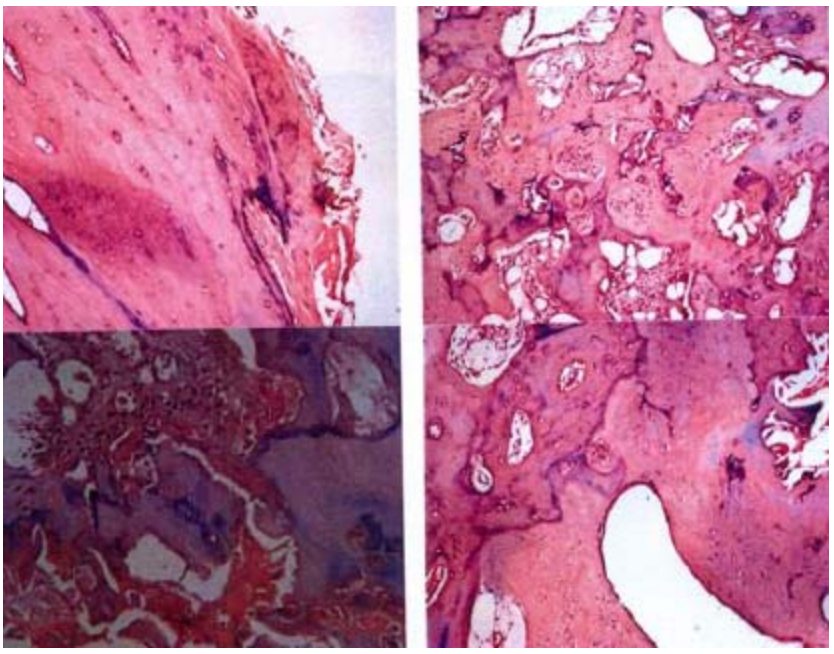

Figure 5. Histopathological examination reveals hypercellular Haversian bone and membranous ossification zones typically described in melorheostosis. 


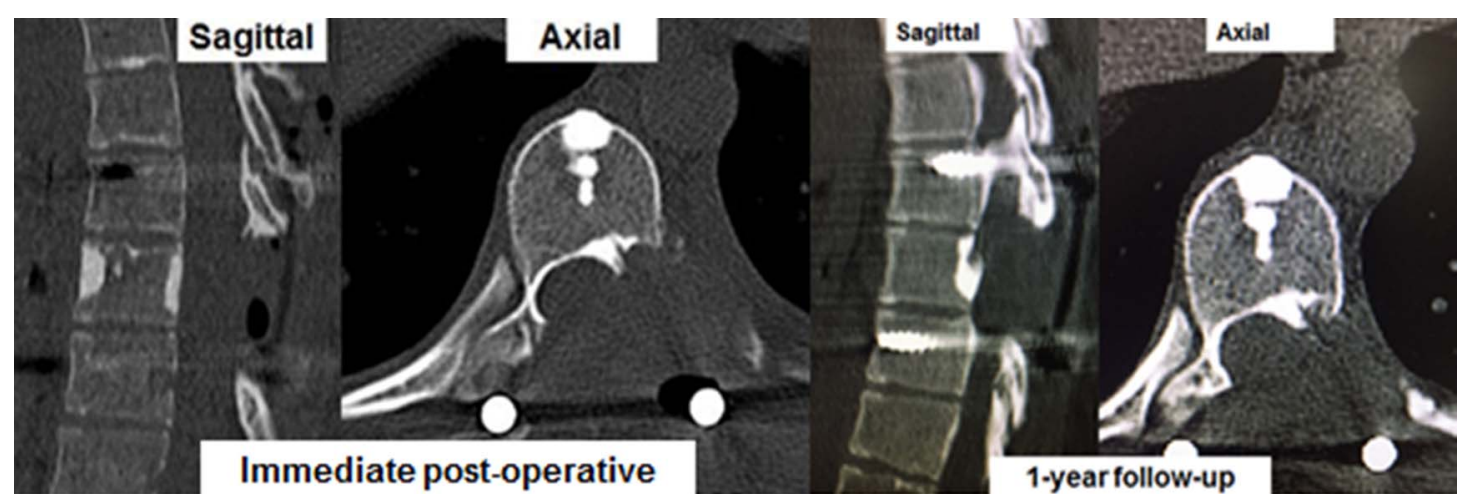

Figure 6. Postoperative computed tomography scan and scan at 1-year follow-up showing complete removal of the lesion with no evidence of recurrence.

Table 1. Brief summary of 5 previously published case reports on surgically managed spinal melorheostosis.

\begin{tabular}{|c|c|c|c|c|c|}
\hline Year & Author & Location & Symptom & Surgery & Outcome \\
\hline 2001 & Exergian et $\mathrm{al}^{3}$ & Thoracolumbar (T12) & Myelopathy with paraparesis & Decompression & $\begin{array}{l}\text { Neurological improvement; } \\
\text { recurrence with neurological } \\
\text { worsening after } 1 \text { year; revision } \\
\text { decompression done }\end{array}$ \\
\hline 2003 & Robertson et $\mathrm{al}^{4}$ & Lumbar (L5) & Axial low back ache & Decompress & Symptomatic improvement \\
\hline 2005 & Zeiller et $\mathrm{al}^{5}$ & Cervicothoracic $(\mathrm{C} 7, \mathrm{~T} 1)$ & Myelopathy with paraparesis & Decompression + fusion & Neurological improvement \\
\hline 2005 & Reznik et $\mathrm{al}^{6}$ & Cervicothoracic (C5-T4) & Myelopathy with paraparesis & Decompression + fusion & Neurological improvement \\
\hline 2013 & Saxena et $\mathrm{al}^{7}$ & Lumbar (L4, L5) & Radiculopathy & Decompression & Symptomatic improvement \\
\hline
\end{tabular}

\section{DISCUSSION}

Melorheostosis is a rare, sclerosing bone dysplasia affecting the young adult population with a reported incidence of 0.9 per million, having no sex predilection. ${ }^{8}$ The condition is classically nonhereditary with exact etiology being unclear where numerous somatic gene mutations have been implicated as a possible cause by various authors. $^{9-12}$ Commonly a disease of the appendicular skeleton with a monostotic or polyostotic presentation, it is mostly confined to 1 limb (monomelic). The involvement of axial skeleton is rare.

In plain radiographs, they have a characteristic "dripping candle wax" appearance. CT and MRI show a sclerotic pattern with a reduction of medullary space and soft tissue involvement (if any). There will be increased uptake in bone scintigraphy, which helps to differentiate it from other sclerosing disorders, such as osteopoikilosis and osteopathia striata, which do not show any scintigraphic abnormalities. Histopathological examination reveals increased osteoid formation with thickened trabeculae and irregular lamellae.

Spinal melorheostosis is seen to affect multiple levels, including the ribs. Symptomatic patients may present with scoliosis, stiffness, back pain, progressive myelopathy, radiculopathy, giddiness, and symptoms of vertebrobasilar insufficiency. Management is largely symptomatic with analgesic medications and physiotherapy. Recently, nitrogencontaining bisphosphonates were also found to be effective, but long-term efficacy is yet to be proven. ${ }^{13}$

Surgical management for spinal melorheostosis has been reported but is exceedingly rare (Table 1). Our patient had left T9-T10 foraminal stenosis due to the encroachment of the lesion along with exiting nerve root compression as evident in CT and MRI. She had complete symptomatic relief following decompression with excision of the lesion. Recurrence is known to occur following surgery in melorheostosis but is commonly reported in the appendicular skeleton; however an exact incidence is unkown. ${ }^{3,14-16}$

\section{CONCLUSIONS}

Melorheostosis is a rare but important differential diagnosis of thoracic radiculopathy and is surgically curable if conservative treatment fails.

\section{REFERENCES}

1. O’Connor RC, Andary MT, Russo RB, DeLano M. Thoracic radiculopathy. Phys Med Rehabil Clin $N$ Am. 2002;13:623-644. 
2. McCarthy M, Mehdian H, Fairbairn KJ, Stevens A. Melorheostosis of the tenth and eleventh thoracic vertebrae crossing the facet joint: a rare cause of back pain. Skeletal Radiol. 2004;33:283-286.

3. Exergian FE, Soare NI, Duncan RW. Vertebral melorheostosis. Case illustration. J Neurosurg Spine. 2001;95:278.

4. Robertson PA, Don AS, Miller MV. Painful lumbosacral melorheostosis treated by fusion. Spine. 2003;28:E234-E238

5. Zeiller SC, Vaccaro AR, Wimberley DW, et al. Severe myelopathy resulting from melorheostosis of the cervicothoracic spine. A case report. J Bone Joint Surg Am. 2005;87:27592762.

6. Reznik M, Fried GW. Myelopathy associated with melorheostosis: a case report. Arch Phys Med Rehabil. 2005;86:1495-1497.

7. Saxena A, Neelakantan A, Jampana R, Sangra M. Melorheostosis causing lumbar radiculopathy: a case report and a review of the literature. Spine J. 2013;13:27

8. Rozencwaig R, Wilson MR, McFarland GB Jr. Melorheostosis. Am J Orthop. 1997;26:83-89.

9. Campbell CJ, Papademetriou T, Bonfiglio M. Melorheostosis. A report of the clinical, roentgenographic, and pathological findings in fourteen cases. J Bone Joint Surg Am. 1968;50:1281-1304.

10. Kim JE, Kim EH, Han EH, et al. A TGF-beta-inducible cell adhesion molecule, betaig-h3, is downregulated in melorheostosis and involved in osteogenesis. $J$ Cell Biochem. 2000;77:169-178

11. Whyte MP, Griffith M, Trani L, et al. Melorheostosis: exome sequencing of an associated dermatosis implicates postzygotic mosaicism of mutated KRAS. Bone. 2017;101:145-155

12. Jha S, Papadakis G, Kim L, et al. Melorheostosis: clinical experience of 23 cases [poster]. Orlando, FL: Endocrine Society, 2017. Abstract

13. Slimani S, Nezzar A, Makhloufi H. Successful treatment of pain in melorheostosis with zoledronate, with improvement on bone scintigraphy. BMJ Case Rep. 2013:pii: bcr2013009820.

14. Smith GC, Pingree MJ, Freeman LA, et al. Melorheos- tosis: a retrospective clinical analysis of 24 patients at the Mayo Clinic. $P M \&$ R. 2016;30:30813-30819.

15. Hasegawa $\mathrm{S}$, Kanda $\mathrm{S}$, Imada $\mathrm{H}$, Yamaguchi $\mathrm{T}$, Akiyama T. Melorheostosis with recurrent soft-tissue components: a histologically confirmed case. Skeletal Radiol. 2017;46:399-404.

16. John B, Sharma A, Pandey RA. Managing recurrence in intraarticular melorheostosis involving the knee joint: a case report. J Orthop Case Rep. 2017;7(5):29-33.

Disclosures and COI: All procedures performed in this study involving human participant were in accordance with the ethical standards of the institution. Informed consent was obtained from the participant included in the study. The study was approved by the Institutional Review Board of Ganga Hospital registered with US Department of Health and Human Services (Regn No. IRB 00004503). The authors received no funding for this study and report no conflicts of interest.

Corresponding Author: Ajoy Prasad Shetty, MS Ortho, DNB Ortho, Senior Consultant, Department of Spine Surgery, Ganga Medical Centre and Hospital Pvt Ltd, Coimbatore, Tamil Nadu, India. Phone: 91 9344833797; Email: ajoyshetty@ gmail.com

Published 30 April 2020

This manuscript is generously published free of charge by ISASS, the International Society for the Advancement of Spine Surgery. Copyright (C) 2020 ISASS. To see more or order reprints or permissions, see http://ijssurgery.com. 